\title{
A new level in a professional training in implementing the educational programs of interactive learning in a digital educational sphere
}

\author{
Alexander Raikov ${ }^{1}$, Kobilzhon Zoidov ${ }^{2}$, Valery Loginova ${ }^{3, *}$, Alexander Chernov $^{4}$, and \\ Vitalia Bortalevich $^{5}$ \\ ${ }^{1}$ RAS, Institute for Control Sciences, 117418 Moscow, Russia \\ ${ }^{2}$ RAS, Laboratory of Integration of the Russian Economy, 117418 Moscow, Russia \\ ${ }^{3} \mathrm{RAS}$, Institute of Market Problems, 117418 Moscow, Russia \\ ${ }^{4}$ RUDN University, 117198 Moscow, Russia \\ ${ }^{5}$ National Institute of Energy Security, 119992 Moscow, Russia
}

\begin{abstract}
The article deals with the complicated system consisted of various aspects of the interactive training which help online operators to reveal and define ways of relation's development between huge sort of electronic data during the interactive training. For instance, they are training, testing, adjustment of tasks, etc. The electronic content is formed in the automated system of the interactive training realized as a part of digital educational sphere. This system is constructed in order to increase the professional skills of the specialists.
\end{abstract}

\section{Introduction}

Designing and implementing successful education programmes of interactive learning is the key to fundamental, wide-ranging educational reforms. The most successful elearning ventures take place in professional training and professional upgrade programs. These goals can only be achieved if training and professional development programs are well done and carefully developed and implemented.

In the modern world nowadays the interactive learning is one of the most fast-growing spheres of education. Moreover, today the educational programs of interactive learning have a relevant role in the formation and development of the skills and abilities of professionals to interact a multicultural market.

To increase the professional level and skills of a specialist there is need to give the interactive education operators (both individuals and software systems) an opportunity to reveal and analyze various electronic data concerning the learner.

For instance, the most important are his personal skills, background knowledge, cultural level, interests, hobbies, specifics of the character and personal motivation.

\footnotetext{
*Corresponding author: loginovalerochka@mail.ru
} 


\section{Problem statement}

It may be realized in two ways: in manual mode or automated mode. The manual mode takes place if the operator is an individual. Then again, if the operator is a software package it is an automated mode.

During the educational process, operators analyze the learner's behavior while interacting with other environmental factors affecting the student (work, rest, personal life, participation in public, political and social activities, collective network games, intellectual time-spending, creating new things, etc.) $[1,2]$.

Another key thing to remember is the significant role of self-made work performed by the student during the educational process.

Such revealed connections of cognitive and personal components may have explicitly and implicitly various sorts of information [3].

Modern information technologies have enabled faster, more reliable and comprehensive data collection [4-6]. As part of the educational process, it is also need to create information databases with information found earlier. Such databases can be used as independent sources of information and can be integrated with other similar databases.

Organizing the fast feedback of the results of such reactions is guarantied by the evaluation service of the interactive training system operators.

Educational module means a training package (including tasks, tests, exercises, materials, etc.) adapted to the certain learner which aim is to make the learner reach the successful results in many various spheres.

In future, it will help the worker to make an innovative solution of the complex professional tasks in complicated and stressful conditions.

This interactively realized educational process is based on the solution by the learners the theoretical and practical tasks of a training package. It is dynamically adapted to a certain sphere of the industry [7].

\section{Solution}

Attributive-semantic analysis helps to analyze the various kinds of tests results on the point how the future worker fits the professional worker model, for instance:

- to state the fact of achieving the certain educational results with an indication of its positive or negative dynamics,

- to determine the structural relationships of cognitive and personality components, changing in the educational process,

- to correct the imprint vector,

- to identify the differences between the programmable model of a industry specialist and the professional model of the worker,

- to reveal the contribution of individual elements of the educational process into building an educational sphere, etc.

This educational process may become a base for supporting new types of cognitivereflexive imprintation. For this purpose there is need to correct the educational process in accordance with the international standards, needs of the state, market, current (political, economic, social, etc.) situation in the world.

What is more, tests results analysis is one of the most important elements of making higher competent and qualified workers. So the participants of the educational process should be provided with:

- test results of the examinees with operator's opinion on the correspondence of the professional model of the employee;

- $\quad$ evaluating the content of test results for specialist's compliance of professional model of the employee; 
- information on the correlation between the versions of an educational modules and / or its components;

- $\quad$ opinions on tests results of other examinees regarding to the test results presented in the system of interactive learning;

- recommendations and any kind of notes to the tests authors to make the educational process better;

- contribution estimates of the different participants to the whole collective results of the educational process.

Then again, traditional approaches to the formation of a professional model of an employee and his/her personal competence are normally and traditionally based on analysis of examine test results of the learner.

If we use the authors' approach, it is possible to find out the estimates of the interactive training system operators in which the educational module was criticized or, on the contrary, had positive assessments.

However, these connections of cognitive and personal components do not have any sort of information on trainee motivations in contrast to Attributive-semantic analysis of the tests results by the end of the interactive education $[8,9]$. Implementation of the authors model allows to optimize process of professional training.

Moreover, while forming a professional model of a worker and his/her personal competences we may use cognitive and personality components of the worker showed during the interactive learning [10-12].

Because of such testing data received helps to analyze thoroughly and evaluate the quality of practical assignments, its influence on workers, to study personalized "portraits" of both individual students and the whole collective. To put it another way, in the end it formulates recommendations and conclusions regarding the profile of personal qualities and professional competences of the worker.

Such steps allow solving a number of new innovative tasks and forming learner's knowledge package and set of skills. Moreover, the results of such testing can be analyzed not only by the interactive training system operators (both software complexes and individuals), but also by teachers and examiners.

\section{Conclusion}

The analysis of various interrelations described in this article is one of the key elements of authors' approach to the formation of the profile of personal characteristics and professional competencies of the professional model of the employee.

Another key point to remember is that using of attributive-semantic methods in the system of interactive learning allows formulating a personalized assessment because of the personal competency matrix.

Overall, the conceptual core of the developed educational system is the transition from the standard one to the open, flexible, organizational system of interactive education within the digital educational sphere.

The theses were prepared with the financial support of the Russian State Scientific Foundation (project No. 16-02-00465a "Development of a mechanism for monitoring, modeling and planning of sectoral development in industry in Russia and the EAEC based on the analysis of cooperative dynamics of aggregated economic entities").

\section{References}

1. A. A. Soldatov, P. V. Sorokin, A. A. Abouellail, I. I. Obach, V. Y. Bortalevich, Y. A. Shinyakov, M. P. Sukhorukov, SIBCON, DOI: 10.1109/SIBCON.2017.7998534 (2017) 
2. A. I. Soldatov, S. O. Ogar, MTT, 100, DOI: 10.1109/SPCMTT.2005.4493206 (2005)

3. A. S. Bugaev, E. L. Loginov, A. N. Raikov, V. N. Saraev, S\&T. Inf. Pr. 36(1), 68 (2009)

4. A. I. Soldatov, A. A. Soldatov, P. V. Sorokin, E. L. Loginov, M. A. Kostina, O. A. Kozhemyak, S. I. Bortalevich, SIBCON, DOI: 10.1109/SIBCON.2016.7491870 (2016)

5. Y. V. Shulgina, A. L. Starostin, M. A. Kostina, T. S. Mylnikova, A. I. Soldatov, MEACS, DOI: 10.1109/MEACS.2015.7414918 (2015)

6. A. I. Soldatov, A. A. Soldatov, M. A. Kostina, V. F. Tolkatchev, J. Phys. Conf. Ser., 671(1), DOI: 10.1088/1742-6596/671/1/012054 (2016)

7. E. L. Loginov, A. N. Raikov, Therm. Eng. 62(4), 233 (2015)

8. A. P. Grigorev, A. I. Soldatov, P. V. Sorokin, MTT, 97 (2000)

9. D. N. Demyanovich, O. S. Vadutov, A. I. Soldatov, MEACS, (2014)

10. H. Shevrin, W. J. Williams, R. E. Marshall, US Pat. №4699153, (1987)

11. G. Benson, I. Slesarenko, P. Shamritskaya, Adv. I. S\&C, 544, 609 (2017)

12. I. Slesarenko, I. Zabrodina, M. Netesova, Adv. I. S\&C, 715, 252 (2018) 